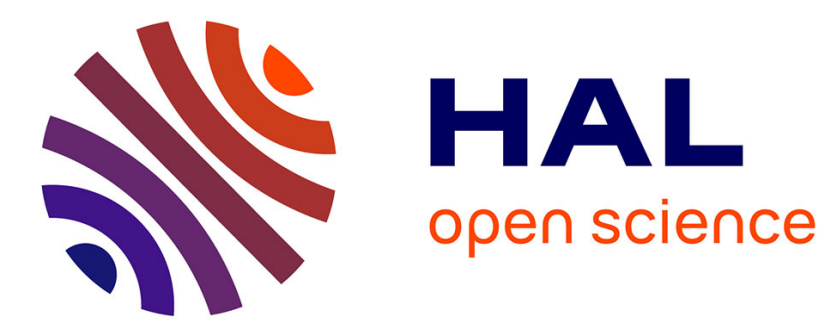

\title{
Innovation in public services: Filling a gap in the literature
}

\author{
Faïz Gallouj, Antonello Zanfei
}

\section{To cite this version:}

Faïz Gallouj, Antonello Zanfei. Innovation in public services: Filling a gap in the literature. Structural Change and Economic Dynamics, 2013, 27, pp.89 - 97. 10.1016/j.strueco.2013.09.002 . halshs01114107

\section{HAL Id: halshs-01114107 https://shs.hal.science/halshs-01114107}

Submitted on 7 Feb 2015

HAL is a multi-disciplinary open access archive for the deposit and dissemination of scientific research documents, whether they are published or not. The documents may come from teaching and research institutions in France or abroad, or from public or private research centers.
L'archive ouverte pluridisciplinaire HAL, est destinée au dépôt et à la diffusion de documents scientifiques de niveau recherche, publiés ou non, émanant des établissements d'enseignement et de recherche français ou étrangers, des laboratoires publics ou privés. 


\title{
(Published in Structural Change and Economic Dynamics : GALLOUJ F., ZANFEI A. (2013), Innovation in public services: Filling a gap in the literature, Structural Change and Economic Dynamics, Vol. 27, December, 89-97)
}

\section{Innovation in public services: Filling a gap in the literature}

\author{
Faïz Gallouj ${ }^{1}$ and Antonello Zanfei $^{2}$ \\ ${ }^{1}$ University of Lille $1 \quad{ }^{2}$ University of Urbino
}

Over the past two decades, after a long period of disregard, the question of innovation in services has continued to grow in importance in the economic literature and political agendas. This new field of "service innovation studies" attempts to free itself from technologist and industrialist conceptions, highlight the role of "invisible" innovation (non-technological innovation in all its forms: organization, process, product, concept, social innovation, etc.) in post-industrial economies. It also focuses on market services. This market bias is visible at both the empirical and theoretical levels, and is also echoed in the international institutions. Thus, although significant efforts have been made to consider specific forms of innovation in services, public services are excluded from the scope of the OECD Oslo Manual and from its various revisions. To paraphrase Ian Miles (Miles, 1998), if services are the "Cinderella" of "innovation studies," we can say that public services are the "Cinderella" of "service innovation studies." This underestimation is sometimes even reflected in the vocabulary used to describe the dynamics of public services. They change, modernize, but do not innovate (or hardly at all).

The objective of this Special Issue of Structural Change and Economic Dynamics is to contribute to fill the gap that can be observed in the literature as regards innovation in public services, at the theoretical, empirical and methodological level. In the following introductory notes, we will first describe the nature of this gap (which we shall refer to as "innovation gap") in academic research and in the statistics. Then we will briefly illustrate how it has been dealt with by the (scanty) previous literature on this topic. Section two will provide a synthetic close-up on each of the articles included in the Special Issue, and section three will conclude.

The core of this collection of papers is drawn from presentations made at the $1^{\text {st }}$ International EIBURS-TAIPS Conference, which was hosted by the Department of Economics, Society and Politics of the University of Urbino (Italy) in April 2012.

\section{The innovation gap in public services}

Public sector accounts for about 20 to $30 \%$ of GDP in most OECD countries (OCDE, 2012). It is a heterogeneous sector which brings together different sub-sectors whose contribution to/and relationships with innovation are various, including: public administration, police, education, health, research, quasi-autonomous (or semi-public) non governmental organisations (the so called "quangos"), and publicly-owned 
commercial organizations. These sub-sectors play a prominent role in the production of services to citizens, communities and business firms, supporting and stimulating other economic activities. Despite this importance of public services in quantitative and strategic terms, except for certain sectors such as health and research, innovation is neglected and under-estimated, even if the amount of works devoted to this question has been steadily increasing over the last few years.

\subsection{The innovation gap and its interpretations}

The innovation gap in public services involves the theoretical, empirical, methodological and political fields. Our purpose here is, on the one hand, to account for how this gap occurs, and on the other hand, to identify a certain number of interpretations of such a paradoxical neglect and under-estimation of innovation in public services.

\section{a) A theoretical gap}

Public sector organisations and their innovative activities are uncomfortable guests in innovation theories. On the one hand, numerous works emphasize the role of public services as supports and catalysts of the innovation dynamics of other economic agents. Some public services (public administrations) provide a regulatory framework for the innovation dynamics in the private sector. Others (public research laboratories, universities) basically contribute to fundamental and applied research. For example, from this double viewpoint (support and contribution) public services hold a central position in system and network theories (Freeman, 1987; Lundvall, 1992; Nelson, 1993; Edquist, 1997, 2005). They occupy a central place in the so-called 'triple helix' model (Etkovitch and Leydersdorff, 2000), which denotes the knowledge production processes in hybrid networks linking universities, firms and government agencies.

On the other hand, innovation dynamics within public administrations remains a largely unexplored "black box" in these models and has been given only little attention, especially in economic literature. Even theories expressly dealing with innovation in services largely disregard the specific nature of public sector innovation. When public services are mentioned in theoretical models, it is generally either in a very indirect way, or only in order to underline their weakness compared with market services. For example, they are not explicitly considered in Barras' reverse cycle model (see Djellal, Gallouj and Miles in this Special Issue), whose purpose is to build a theory of innovation in market services, even though many of the conceptual tools introduced in this model were derived from empirical investigations in local public administrations. Similarly, when considering sectoral taxonomies, public services are excluded from Pavitt's taxonomy of technological trajectories (Pavitt, 1984). On the other hand, in their attempt to generalize this taxonomy to services, Soete and Miozzo (1990) emphasize public services are supplier-dominated. In other terms public services are perceived as passive adopters of innovations produced in the private (manufacturing) sector.

\section{b) An empirical gap}


Empirical works devoted to the innovation dynamics in public administrations have long been scarce. The incompatibility of innovation and public services was even expressed at the semantic level: the term innovation was often considered taboo and replaced by "change" or "modernization". One shouldn't forget that in the Schumpeterian tradition, innovation is defined as the socialization of invention, i.e. its encounter with the market, while public services are provided outside the market.

It should be acknowledged that this gap doesn't hold for a limited number of public services, especially health and research. The literature on innovation in such services is abundant. It should be noted however that these studies generally emphasise the role of science and technology-based innovation. This is particularly problematic in the case of hospitals which are package complex services, combining elementary services not only in the field of health care, but also in many other fields (hostelry, catering, transport, cleaning, etc.), which may involve a variety of innovation dynamics, well beyond scientific research in bio-medical areas (Djellal and Gallouj, 2005). Another area in which the innovation gap has significantly reduced in recent times concerns applications of ICTs in public administrations including the development web based public services. Here empirical studies have proliferated over the past decades, although contributions have grown more in some research domains (computer science and engineering) than in others (social sciences in general and economics in particular). Moreover, studies have focused almost exclusively on eGovernment, thus largely disregarding other public eService categories (such as eHealth, Intelligent Transport Systems, eEducation) and very limited comparable data are available across countries (Arduini and Zanfei, 2013).

The empirical gap also makes itself felt through the scarcity of surveys on innovation in public services, which have instead become relatively abundant in the field of private services (as in the case of the Community Innovation Surveys). The OECD Oslo Manual, which provides the international guidelines for innovation surveys, doesn't cover the public service sector. Paradoxically public administrations have developed numerous methods for evaluating innovation in other economic sectors. However they have only very recently expressed some interest in the evaluation of their own innovation. This is the syndrome of the "poorly shod shoemaker". This syndrome holds not only for the category of public services which are traditionally forgotten in innovations studies (for example public administrations), but also for subsectors which innovation activities are acknowledged (for example health and education). Of course it doesn't hold for research laboratories and universities which are evaluated by a large set of indicators (number of scientific publications, patents, etc.).

When innovation is taken into account in public services, another source of empirical gap may arise. It concerns the nature of innovation. In fact, the focus is on innovations which target efficiency rather than effectiveness, as far as, in the absence of profit, the product of public services is defined as a sum of expenses. As Potts (2009) rightly points out, public services are considered effective when they are efficient. Therefore the innovation gap is closely linked to another gap: a performance gap. Innovation in public services has long been envisaged in terms of a cost-cutting trajectory at the expense of other performance trajectories. However the performance in public services may take different forms, other than the mere cost reduction and output growth. According to the value system favoured, the very definition of output changes and the 
assessment of pure quantitative performance may not be satisfactory as more qualitative dimensions need be considered including social, civic, reputational aspects. Innovation and value creation in public services may thus be linked to the creation of inter-personal relationships, trust, empathy, inclusion, equality and fairness. The seek for such types of performance may guide innovation trajectories in public services towards particular forms of innovation, e.g. social innovation, environment-friendly new services, ad hoc and customised services.

The empirical gap doesn't only concern the nature of innovation. It also concerns the actors involved in the innovation process. The dominant vision had long been that in public services innovation is a top-down process, which is initiated by political decisions at the highest level and implemented by senior management (Hartley, 2005). However this vision is challenged as far as more and more innovations derive from bottom-up process and are initiated by middle management and front-line staff, or are stimulated if not designed and tested by end users (as in the case of web based services).

\section{c) Interpreting and bridging the innovation gap}

The reasons for this paradoxical idea that public services (and more generally nonmarket services) are not (or less) concerned with the issue of innovation are numerous and well known. We briefly recall some of them:

1. The non-market dimension. Public services are provided, for the most part, free of charge. They are not sold on the market and they are not driven by profit seeking motives. They are largely funded through taxation (which is a scarce resource) and not by their sales. There is no economic incentive to conquer market shares thanks to innovation, as it is the case for goods and market services. However, it should be noticed that the free nature doesn't hold for the whole range of public services, some of which could be sold and actually are. This is for example the case of education and health. Furthermore, as was emphasized previously, public services have social, civic, ethic motivations which may lead to specific forms of innovation.

2. The lack of competition. Public organisations provide citizens, firms and other institutions with services that the market fails to provide efficiently or equitably. This frequently occurs under (quasi) monopoly conditions or in highly regulated contexts wherein public organizations most often play an incumbent, dominant role. Given market failures, public services are supposed to behave as lazy monopolies. However, it should be recalled that this argument of the lazy monopoly is partially challenged by the contestable market theory (Baumol), which underlines that the monopoly is prompted to behave competitively by the simple threat of potential entrants on the market. Many public services can be contested, and furthermore a special form of competition also occurs on the policy market, which urge public bodies to seek for effectiveness and efficiency.

3. Risk aversion. It is risk aversion which has guided innovation trajectories towards efficiency objectives at the expense of more general effectiveness ones. Such a culture of risk aversion, which is frequently mentioned in the literature as a characteristic of public sector (Mulgan and Albury, 2003; Ross et al., 2004; Potts, 2009), may be a barrier to innovation. 
4. The nature of appropriation regimes. Public services (even when innovative) are intended to be diffused the more widely as possible. They cannot (and should not) be privately appropriated, while private appropriation of innovation is supposed to be an incentive to innovation through the temporary monopoly it provides. Public organizations can thus be expected to be less innovative than private ones because of this difference in appropriability and incentive structures.

5. Rigidity and bureaucratic inertia. The organisations that provide public services are generally regarded as rigid, while productivity and innovation require some flexibility. There are many explanations for this inertia. Firstly, public service managers are obliged to adhere to rigid procedures that exist in order to safeguard the principles of equality between citizens (in terms of the location of infrastructure, recruitment, universality of services). Secondly, they have less freedom to substitute resources especially labour and capital (Knox Lovell, 2002, Dunleavy et al.2006). Furthermore, public service managers, as Fox (1999) notes, have no control over the mix of services provided, unlike their private-sector counterparts. They have only limited freedom to influence the nature of the product provided. They cannot, on their own initiative, stop providing a service or offer a different one. Consequently, they have only limited control over resource allocation and thus limited influence over performance and innovation.

\subsection{Bridging the innovation gap: why and how?}

Our purpose is now, on the one hand, to examine the main factors explaining the recent renewed interest in innovation in public services, and on the other hand, to give a brief overview of the main scientific trajectories implemented in the literature in order to the fill the gap.

\section{a) Some explanations of renewed interest in innovation in public services}

The renewed interest in innovation in public services may be explained by a number of factors which are not independent and which we will evoke quickly:

- Technological factors. Services and particularly public services (which are often large organizations, processing information) are among the main adopters of Information and Communication Technologies (Van Reenen et al. 2010). The availability and evolution of new infrastructures and web based applications is per se inducing important innovation dynamics, as they facilitate the adoption of modern techniques and methods in public management; contribute to enhancing accountability, openness and transparency of Public Administrations; and promote interactive government-citizens processes.

- Economic factors. The public sector is facing a number of economic challenges, including increasing demands from citizens and businesses, growing knowledge based competition on a global scale, and stricter budgetary constraints that increase the difficulty of maintaining service levels. The economic crisis puts further pressure on State budgets and induces changes and innovations which seek to cut cost while 
maintaining or increasing the quality of the service provided. Similarly it induces social innovations providing social support and assistance for disadvantaged social groups.

- Socio-demographic factors. Population ageing and lifestyle health challenges (for example diabetes, obesity) which characterise all developed countries are important drivers of innovation dynamics in public services. The rise of environmental and ecological concerns is also increasingly inducing the public sector to invest in innovative fields and promote the adoption of green technology (Gauthier and Meyronin, 2008).

\section{b) Various modalities for bridging the innovation gap}

The innovation gap began narrowing in different ways through the multiplication of empirical investigations.

The first path pursued in order to narrow the innovation gap is the reconsideration of the relationship between public services and the adoption of technological innovation. This relation is now envisaged in more complex terms than a simple adoption relationship geared towards an efficiency logic. In fact, ICTs are endogenized within public services and their efficiency as well as their ability to generate innovation are heavily dependent on organizational and skills complementary dynamics (see Seri and Zanfei's and Arduini et al.'s papers in this volume). ICT based innovations cannot anymore be reduced to the adoption of technical systems in order to achieve cost-reducing efficiency gains. They also pursue other objectives such as for example the generalized access to innovation in space and time, the adaptation to the users' specific needs (tailor-made services), and even user driven innovation.

The implementation of New Public Management from the 1980s 1990s onward can also be interpreted as an attempt to bridge the innovation gap in an assimilation perspective (assimilation of the public sector to the private sector). It can be considered as a general form of innovation reflected in the reduction of the hierarchical structures and the transposition to public services of management methods used in private sector, for example, outsourcing, performance targets, quality management, (public) marketing. However it can also be envisaged as a general context conducive to various innovation dynamics. In other words, in such a perspective, the NPM methods are not anymore perceived as innovations, but as drivers of innovation.

In order to fill the gap, the literature increasingly draws on a demarcation perspective which involves the empirical identification of forms of innovation specific to public services. For example, as we shall see, in this Special Issue, Bloch and Bugge adopt a cautious demarcation perspective. In order to allow comparisons with private sectors, they essentially keep the Oslo Manual's types of innovation, only adjusting their content to public services. On the other hand, other contributions are more demarcative as far as they introduce new types of innovation, specific to public services. For example, the Audit Commission (2007) suggests "democratic innovations" defined as new practices that increase democratic engagement with citizens. Halvorsen et al. (2005) within the PUBLIN European project identify the following categories: System innovations (for instance by the establishment of new organisations or new patterns of 
co-operation and interaction); Conceptual innovations (for example integrated water management or mobility leasing); and Radical changes of rationality (change in the world view of the employees of an organisation). Hartley (2005) suggests to add to product, service and process innovations the following ones: Position innovation (involving new contexts, customers or partners for services); Strategic innovation (with new goals, purposes or values); Governance innovation (for example new democratic institutions and forms of participation); and Rhetoric innovation (where new language, concepts and definitions are applied).

The question of measuring innovation in public services is still in its infancy. However a certain number of interesting experiments have been carried out. Arundel and Huber's paper in this Special Issue provides a state of the art which identifies 15 surveys and other large-scale data sources and classifies them into three groups according to the research method adopted: 1) object-based studies focused on particular innovation cases implemented in public service organizations; 2) business practice surveys in which public service managers are queried about their use of specific innovative business practices and technological innovations; 3) innovation surveys which focus on the introduction of given typologies of innovation, often inspired by the Oslo Manual. The European Commission has funded several important projects on innovation in public services: PUBLIN, MEPIN, ServPPIN.

In the literature, the question of public-private innovation networks in services (PPINs), which lies at the heart of the ServPPIN project, is probably one of the most recent modalities for bridging the innovation gap in public services. PPINS describe cooperations for innovation between public and private service organizations (Gallouj, Rubalcaba et Windrum, 2013). The concept of PPIN in services allows to enrich the traditional concept of innovation network in various ways. It opens it up to new actors: all market services and third sector organizations. It extends the possible forms of participation for different public and private actors. Thus public organizations are no longer confined to a support role in the innovation process; rather, they may be active participants in that process, particularly as far as their own activity is concerned. It also extends the range of purposes for which networks are established. Technological innovation is no longer the sole objective, since non-technological innovation in all its forms (organizational, product, process, social), particularly innovation in public services, is now included in the model.

\section{Content of the Special Issue}

The first paper, authored by Faridah Djellal, Faïz Gallouj and Ian Miles, provides an introduction to the key issues and debates that have raged in the services innovation literature over the last 20 years and a discussion of the place of public services in these debates. It provides a background for the other papers, and brings them into focus. This paper is based on a simple but particularly suggestive analytical framework, which takes account of the differences and similarities in the way to address the innovation potential in manufacturing and service activities.

The debate on innovation in services, either theoretical, empirical, methodological, managerial or political is often addressed according to the different following analytical 
perspectives assimilation / demarcation / inversion / integration (Gallouj, 2010). The 'assimilation' viewpoint addresses innovation in services in terms similar to innovation manufacturing, focusing on technological innovation. It leads to the conclusion that services are innovation laggards and subordinate to suppliers (Pavitt, 1984). The 'demarcation' viewpoint is the antithesis of the assimilation view. It is focused on the seek for particular forms and modes of innovation which are invisible to the strictly assimilationist/technologist gaze. The inversion perspective, for its part, marks an inversion of the balance of power between manufacturing and services. It seeks to account for innovation dynamics where certain services (Knowledge Intensive Business Services) support the innovation activities of other sectors (especially manufacturing sectors) and may even dominate them. The 'integration' (or 'synthesis') viewpoint, as outlined by Gallouj and Weinstein (1997), seeks to take the recent insights of demarcation literature and to integrate these within insights gained in manufacturing studies within a unifying innovation framework. It is based on a Lancasterian characteristics-based approach of the product, which defines any good or service as linking different vectors of characteristics (service, technical, competence characteristics) and innovation as actions on the vectors.

Djellal et al.'s paper shows that this analytical framework (assimilation/demarcation/inversion/integration) can be used in order to provide a state of the art of innovation in public services. However, its application requires some additional reflections. For instance, in the case of the assimilationist perspective, the authors find it appropriate to distinguish between at least two different groups: first, the science-based public services (public research laboratories, universities, certain aspects of hospital services) and, secondly, less science-based activities. The idea of assimilation seems inappropriate in this case; this type of innovation has much in common with innovation in (high-tech) industry and, indeed, a mainly technological focus may be largely justified. The dynamics of innovation in the second group, the other public service sectors (e.g., governments), in contrast, fit better into the traditional assimilationist perspective as manifested in the less innovative market services. This is a perspective centred on technological innovation that is adopted rather than produced, instead of other more specific, non-technological forms of innovation. The inversion perspective also requires a nuanced interpretation, the authors remark. Public services influence innovation in other sectors in different ways. This is true not only for sciencebased public services (public laboratories, etc.), but also for government agencies that support innovation or governments that use public procurement to guide innovation trajectories. These specificities (whether they concern the nature of the innovation or the organisational methods) are considered from a double differentiation perspective: differentiation with respect to manufacturing and differentiation with respect to market services. But demarcation need not be the end of the story: public services should also fit into the integrative theoretical models. The authors submit that characteristics-based approaches can provide interesting avenues of research for that purpose.

The second paper, by Maria Savona and Edward Steinmueller, intends to enrich the characteristics-based approach of the product and of innovation (Gallouj and Weinstein, 1997) in different ways. Savona and Steinmueller suggest to introduce two further vectors of characteristics related to both provider and customer: time and information vectors. In Gallouj and Weinstein's representation, it should be recalled, coproduction is 
illustrated by the relationship between a column vector of provider's competences and a row vector of customer's competences. The introduction of a time vector allows here to account for the different levels of co-production that the consumer and the provider can choose. The use of the customer's time (or its saving) in the service (co-)production is therefore envisaged according to three levels: self-production, co-production and purchase. The introduction of the information vector is, for its part, a way to isolate (from the vector of technological characteristics) ICTs which play, as we know, a fundamental role in the production and delivery of services (and especially public services).

The new characteristics-based representation proposed allows to envisage innovation in services "as a time-saving process resulting from the (changing degree of) coproduction of service provider and customer." It addresses productivity gains as "time-saving changes in the production and consumption of services". It is used to re-interpret the Barras reverse cycle model, well know as an attempt to build a theory of innovation services (see Djellal et al.'s contribution in this volume). According to Savona and Steinmueller, the first two phases of the reverse cycle (the phase which aims at efficiency and effectiveness through process innovations) seem to be confirmed but also to constitute "the ends of the story". On the other hand, the phase of product innovation, which supposes a greater involvement of the customer, is problematic regarding public services. This analysis is confirmed in the case of several British e-government services experiments, particularly NHS Direct (a website that provides expert health advice online and by phone) and Direct-Gov (large and multi-purpose site devoted to various fields of public administration).

The next two papers (Carter Bloch and Markus Bugge's contribution, on the one hand, and Anthony Arundel and Dorothea Huber, on the other hand) are devoted to the question of measurement of innovation in public services. The theoretical and empirical gap that characterizes the question of innovation in public services is quite naturally reflected in a methodological and institutional gap. Indeed, there are neither official indicators adapted to innovation in public services, nor recurrent official surveys such as Community Innovation Surveys. Therefore our knowledge on that issue mainly stems from case studies. Large-scale surveys allowing to establish generalizable results and comparisons at different levels are necessary for public services. The papers by Bloch and Bugge, on the one hand, and Arundel and Huber, on the other hand, propose such surveys on an exploratory basis.

Carter Bloch and Markus Bugge's contribution is based on the result of a pilot study on the development of a measurement framework for innovation in public services. This study was carried out in the five Nordic countries (Denmark, Finland, Iceland, Norway and Sweden) within the EU-funded MEPIN project (Measuring Public Sector Innovation in the Nordic Countries). It is made up of two parts: the first part consists in the definition of innovation indicators adapted to public services, and the second part in the implementation of these indicators within a questionnaire and survey.

Regarding the first step, on the basis of interviews with representatives of public sector organizations and policy users, the authors assess to what extent (and with what kind of 
changes) Oslo Manual indicators (i.e. product, process, organizational and market innovation) may be generalized to innovation in public services. The conclusion of their analysis is to maintain the Oslo typology provided that some semantic changes are made in order to take account of public services specificities. For example, it is suggested to replace market innovation by communication innovation, which describes different modes of promotion of their activities by public services. Communication innovation covers three different types of innovation: "new methods of promoting the organisation or its services, new methods to influence the behaviour of user, and first time commercialisation of goods and services". On the other hand the definitions of product and process innovation are close to the Oslo Manual's definition although they leave more room to non-technological forms of innovation.

Regarding the second step, Bloch and Bugge draw on the CIS questionnaire as regards the large part of the topics addressed (forms of innovation, innovation activities and expenditures, objectives, cooperation, external funding). However they add questions specifically designed for public services (innovation drivers and barriers, information channels for innovation activities, innovation strategies and capabilities, innovative public procurement). It should be noted that the questionnaire raises important methodological problems: for example, the definition of the target population, the identification of the relevant statistical unit are made difficult by the complex structure of public organizations.

The questionnaire was administered in 2010 to public service institutions at different levels: central, regional and local. It provided relatively coherent results across countries. The main result which should be underlined is the high share of innovative organisations (80 à $90 \%$ of the respondents reported that they have introduced at least one type of innovation during the last two years (2008-2009). This result is counterintuitive given the innovation gap in public services underlined above. This share of innovative organizations is even higher than the share in private services (see SIS). However it should be noted that it is confirmed by other studies. For example, the 2010 Innobarometer survey (European Commission, 2011) shows that more than $90 \%$ of European public sector organizations (Sample of 3699 organizations) have introduced an innovation over a two-year period. Several arguments are mentioned to explain such a paradoxical result: First, a soft interpretation of what innovation is by public managers, less used to such a phenomenon than private managers (tendency to confuse innovation and change), then a relatively higher share of large organization (more prone to innovate) in the public sector than in the private sector, finally a perpetual adjustment of public organizations due to regulatory and political change.

The paper by Arundel and Huber conducts a similar exercise in the case of Australia. In the same way, the authors first draw on interviews with 37 branch level managers in the Australian Government in order to understand what innovation in public services is. Then they launch a pilot survey (344 respondents) on the basis of the definitions and indicators previously established. The questionnaire administered between August and September 2012 distinguishes four types innovations: 1) processes, 2) products and services, 2) communication and policy innovations. In comparison with the typology used by Bloch and Bugge, it should be noted that organisational innovation is excluded and that a new category (policy innovation) is added. Excluding organizational 
innovation is justified by the difficulty to distinguish process innovation from organizational innovation. It should also be noted that each type of innovation is subdivided in several sub-categories (from three to five subcategories) and that the questionnaire includes an open question allowing the respondent, for each innovation type, to add potential other sub-categories. In order to try and explain the very high innovation rates established in the previous surveys (and particularly MEPIN and the 2010 Innobarometer), the questionnaire includes several questions seeking to make a distinction between minor changes and more significant innovations (for example questions about the number of person month involved in the production of innovation, is it a "country first" innovation? etc.).

The same paradoxical result (i.e. a high innovation rate) applies here. The share of the entities which report to have introduced at least one type of innovation over the two last years is $91.3 \%$. The main interpretation of this result is that minor innovations (which generally requires less person months for their development and which are not "Australia-first" innovations) are over-represented. As a matter of fact, the cognitive interviews carried out show that interviewees have difficulties to distinguish the changes which are innovations and the ones which are not. Therefore, if the analysis was limited to significant innovations, the innovation share would be significantly lower. It is evaluated at about $60 \%$. Another interpretation is that the sample is likely to be biased towards innovative branches. Indeed, it is likely that the managers of the non innovating branches are less prone than others to answer the questionnaire.

The last two papers are devoted to innovation in public administration from the perspective of the interaction (complementarity) between ICT introduction, human capital investment and organizational change. Both of them draw on an important dataprocessing and econometric work.

Seri and Zanfei's paper addresses this question from the viewpoint of the impacts of ICT on performance of public sectors at the national level. This question, which is often tackled from the perspective of the well know Solow paradox, has been the object of an extensive literature in the field of manufacturing and private services. The main conclusion of this literature is that, in order to impact on productivity, ICT investments must be combined with actions on human capital and organization. On the other hand, there are very few contributions addressing this issue in the case of public services, although they are among the main ICT adopters (they are more ICT intensive than manufacturing and market services). Previous analyses have been carried out with a narrow focus in terms of public sector establishments and activities (e.g. primary schools or police departments) and in terms of country coverage (normally individual countries). Due to data shortage, the more analyses are extensive in terms of public services and country coverage, the less conclusive is the extant evidence of the actual impact of ICT on public sector performance. The role of skills and organizational factors, and their interaction with ICT adoption, are even harder to assess when it comes to cross-country analyses. The main problem that has hampered cross-country analyses on this important topic of the co-evolution of ICTs, skills and organization is the difficulty to measure output and productivity in public services. Seri and Zanfei's paper contributes to fill this gap in the literature, by constructing a panel of comparable data on the performance of public administrations (PAs) in 16 European countries in 2003- 
2007. They develop a quality adjusted output index which draws on per capita PA expenditures net of Defence, based on the hypothesis that the adoption of public eservices (as measured by Eurostat) can be considered as a proxy of output quality. Indeed such an adoption can be considered as an indicator of the ability of PAs to introduce innovative services that are considered of interest by users. Organizational change is measured by the weighted average of Public-e-service online availability index computed by Capgemini et al (2010), where weights are represented by the degree of sophistication of services. The underlying assumption is that the introduction of e-services is the source of significant change in the organization of PAs. Data on ICTs investments and on skill levels of employees, for their part, are drawn from EUKLEMS data set in the form of "PA investment in ICT on total population" and a "Human capital index ".

Overall, on the basis of an econometric analysis, this paper shows that the complementarity between ICT investments, organizational change and human capital is an important condition for performance in public services as well. Given the particular nature of public services (variety of actors, coproduction) and given the specificities of their objectives (value systems), it appears that, in the case of public services, investment in human capital and organizational change play a particularly important role as drivers of performance. The neglect of organizational and human dynamics in favour of technological dynamics is likely to favour a performance gap (the Solow paradox).

Last but not least, the paper by Davide Arduini, Mario Denni, Matteo Lucchese, Alessandra Nurra and Antonello Zanfei also departs from the hypothesis that «innovation is not only a matter of technical change ». It is an old hypothesis in economic literature, which sparks a renewed interest in the context of ICTs pervasive diffusion. This paper builds on the "technology enactment" framework introduced by Fountain (2005) to analyze the co-existence of technical, organizational, and contextual factors in the diffusion of e-Government, with specific reference to services provided by Italian municipalities. Consistent with this framework the authors particularly emphasize the role of both competence accumulation within PAs and outsourcing of ICT activities. This helps highlight the complexities of knowledge management in the process of new service development. On the one hand, internal training and skill upgrading are necessary for PAs to engage in e-service design and provision. On the other hand, they are needed to accumulate absorptive capacity and gain access to external competencies that are complementary and essential in the process of eGovernment development and diffusion.

Arduini et al. also highlight some factors that are only marginally considered in the technology enactment scheme, that have to do with the role of users and demand factors. While Fountain (2005) does acknowledge the importance of contextual factors, her emphasis is on the supply side. She assigns a key role to organizational factors within PAs and to the relationships with policy makers and vendors of technology. Limited attention is given to users of ICTs and e-Government services that are external to PAs, namely citizens, firms and other institutions. In this framework, users are substantially seen as constraints to PAs' action: they are viewed as either passive adopters or as an extra-cost that PAs must take into account when delivering new services. Arduni et al. submit that this view is being largely overtaken by the current 
evolution of digital networks, which is increasingly characterized by the direct involvement of users in defining the rate and direction of e-Government development. They thus suggest that e-Government development can hardly be understood by looking exclusively or mainly at the internal organization of PAs. This entails that more attention should be given to the demand side, to capture those contextual factors that increasingly contribute to e-service design, implementation, and diffusion.

The paper is based on data drawn from the 2007 and 2009 Istat ICT-PA surveys on «Information and Communication Technologies in Local Public Administrations ». The data set includes information on 4,471 Italian municipalities.

In the empirical model tested in this paper, the dependent variable (the provision of eGovernment services) is a composite indicator describing the number and the quality of e-services offered by municipalities. The independent variables selected are classified into three categories: 1) technological factors which include the technologies used to provide e-services (they are represented by following dummies: broadband access, smart card players); 2) organizational factors which describe the capacity of PAs to embed (endogenize) technologies (they are represented by following dummies: ICT training, ICT in-house, ICT outsourcing, Municipal size); 3) contextual factors, which express the role of demand in the development of e-government services. The dummies used in this case are the territorial dispersion of the population, the growth rate of elderly people, the number of patents which expresses the innovativeness of the geographical area.

The main results of the econometric analysis are the following ones:

- The adoption of e-governement services is positively correlated with the outsourcing of ICT competences and activities, but much more with their in-house accumulation.

- The adoption of e-services is less frequent in a certain number of situations including: small size municipalities, sparsely populated areas and higher elderly people growth rates.

- Conversely, the diffusion of e-government is more frequent in geographic areas characterized by a more intensive patenting activity, which favours a dynamic and more sophisticated demand for new public services.

\section{Conclusion: the contribution of this Special Issue to filling the innovation gap}

As illustrated in the previous sections, different efforts have been made in the direction of a better understanding of innovation in public services. This Special Issue contributes to filling the innovation gap in at least two ways.

First, some substantial refinements and departures are proposed vis a vis the existing frameworks and concepts that were developed to analyse innovation in private services. Conceptual refinements include the following: the application to the analysis of public services of the "assimilation/demarcation/inversion/synthesis" perspective, that has previously been employed to interpret innovation in services, going beyond a mere variant of innovation in manufacturing industry (Djellal, Gallouj and Miles); a reconsideration of the analytical category of service "co-production", to take into account the investments in time and information gathering by service users that are necessarily involved in this process (Savona and Steinmueller); the re-conceptualization 
of performance of service providers in the absence of market prices and of the specific interactions between technical progress and organizational change in the public sector (Seri and Zanfei). It is important to note that addressing these topics does not only imply an adaptation of extant analytical categories developed in the broader field of innovation in general and of service innovation in particular. These studies also highlight some theoretical aspects that are inspired by the specific analysis of public sector innovation and may be of more general interest. Examples of these latter aspects of public service innovation refer to: the societal nature of objectives that lead to the introduction of new public services, with implications on the time horizon and incentives to innovate of public actors; the interdependencies between the development of new services and government interventions to favour the generation and diffusion of key technologies; new design approaches and organizational practices that are necessitated by the complex relations between actors involved in public service development, which has implications for the analysis of "open innovation" in other sectors.

Second, this Special Issue provides sound evidence on the nature and determinants of, as well as barriers to, the development and diffusion of public service innovation. This fills an important gap in the literature that is the consequence of data limitations and previously unresolved measurement issues. The selected papers tackle these (measurement and data) problems in several ways and at different levels of aggregation. At the national level, available data on (non-defence) indicators of e-service adoption and input costs are utilized to construct proxies of the performance of public administrations in EU countries (Seri and Zanfei); a pilot survey on the generation and diffusion of public sector innovation in Nordic countries has been used to better capture the specificities of public services (Bloch and Bugge); a novel survey conducted in Australia sheds light on how public managers perceive different types of innovation and measures the intensity and quality of innovation efforts that are actually carried out (Arundel and Huber). At the local level, illustrative evidence through case studies is provided on the co-creation of eGovernment services in the UK (Savona and Steinmueller); and an extensive dataset has been utilized to analyse how technical, organizational change and contextual factors affect e-Government diffusion in Italian municipalities (Arduini et al.).

\section{References}

Arduini, D., Belotti, F., Denni, M., Giungato, G., Zanfei, A. (2010). Technology Adoption and Innovation in Public Services. The Case of e-Government in Italy. Information Economics and Policy, 22, pp. 257-275.

Arduini D. and Zanfei A. (2013) An overview of scholarly research on public eservices. A Meta-analysis of the literature Telecommunications Policy, forthcoming 2013

Audit Commission (2007), Seeing the light. Innovation in local public services, Local government national report. Capgemini, IDC, Rand Europe, Sogeti and DTI (2010) Digitizing Public Services in Europe: Putting ambition into action, 9th Benchmark Measurement, European Commission, Directorate General for Information Society and Media, Brussels. 
Coombs R. and Miles I. (2000), Innovation measurement and services: the new problematique, in Metcalfe S. and Miles I. (eds) Innovation systems in the service economy. Measurement and case study analysis, Kluwer, Boston, p. 85-103.

Djellal F. and Gallouj F. (2005), Mapping innovation dynamics in hospitals, Research Policy, Vol. 34, 817-835.

Dunleavy, P., Margetts, H., Bastow, S. and Tinkler, J. (2006) "Digital Era Governance". Oxford: Oxford University Press

Edquist C. (ed) (1997), Systems of Innovation: technologies, Institutions and Organizations, Pinter.

Edquist C. (2005), Systems of Innovation: Perspectives and Challenges. In The Oxford Handbook of Innovation, ed. J. Fagerberg; D.C. Mowery; and R.R. Nelson, 181-208: Oxford University Press.

Etzkovitz H. et Leydesdorff L. (2000), The dynamics of innovation from national systems and ,'Mode 2' to a triple helix of university-industry-government relations, Research Policy, 29, p. 109-123.

European Commission (2010), 2010 Innobarometer, Flash Eurobarometer ${ }^{\circ} 305$.

Fountain, J.E. (2005). Enacting Technology in Networked Governance: Developmental Processes of Cross-Agency Arrangements. Bond University Working Paper Series.

Bond University, School of Business, Queensland, Australia.

Fox, K.J., "Efficiency at different levels of aggregation: public vs. private sector firms", Economic Letters, 65 (2), 1999, p. 17-176.

Freeman C. (1987), Technology policy and economic performance: lessons from Japan, Pinter, London.

Gallouj and Weinstein (1997), Innovation in services, Research Policy, 26 (4-5), pp. 537-556.

Gallouj F. (2010), Services innovation: assimilation, differentiation, inversion and integration, in Bidgoli H. (ed), The Handbook of Technology Management, John Wiley and Sons, p. 989-1000, Hoboken, New Jersey.

Gallouj F., Rubalcaba L., Windrum P. (2013), Public-Private innovation networks in services, Edward Elgar Publishers.

Gauthier C., Meyronin B. (2008), Nouveaux services publics et développement durable: une approche exploratoire [New public services and sustainable development: an exploratory approach], Working Paper $n^{\circ} 833$, Centre d'études et de recherche sur les organisations et la gestion, University Aix Marseille, Paul Césanne.

Hartley J. (2005), 'Innovation in governance and public services: Past and present' Public Money and Management 25: 27-34

Knox Lovell, C.A., "Performance assessment in the public sector", in Fox, K. (ed.), Efficiency in the public sector, Dordrecht, Kluwer Academic Publishers, 2002, p. 1135 .

Lundvall, B- $\AA$ (ed) (1992), National Systems of Innovation. Towards a Theory of Innovation and Interactive Learning. London: Pinter.

Miles I. (1998), Services, Systems and Innovation - Cinderella comes to the ball, Services and Systems Worksop, CRIC, Manchester, March.

Mulgan, G. and Albury, D. (2003), Innovation in the Public Sector, Strategy Unit, Cabinet Office, October 2003

Nelson R. (ed) (1993), National innovation systems, Oxford University Press.

OECD (2012), http://stats.oecd.org/glossary/detail.asp?ID=2199. 
Pavitt, K. (1984), 'Sectoral Patterns of Technical Change: Towards a Taxonomy and a Theory. Research Policy, 13, 343-374.

Potts (2009), The innovation deficit in public services: the curious problem of too much efficiency and not enough waste and failure, Innovation: management, policy and practice, 11, p. 34-43.

Ross, V.E., A.W. Kleingeld and L. Lorenzen L. (2004), 'A Topographical Map of the Innovation Landscape'. The Innovation Journal: The Public Sector Innovation Journal, 9(2), 1-19.

Soete, L. and M. Miozzo (1990), Trade and Development in Services: a Technological Perspective. Maastricht Economic Research Institute on Innovation and Technology (MERIT) Working paper 89-031

Van Reenen J.V, Bloom N., Draca M., Kretschmer T., Sadun R. (2010), The Economic Impact of ICT, Final Report, CEP, London.

Windrum P. (2008), Innovation and entrepreneurship in public services, in Windrum P. Koch P. (eds), p. 3-20.

Windrum P., Koch P. (eds) (2008), Innovation in Public Sector Services: Entrepreneurship, Creativity and Management, Edward Elgar Publishers. 